\title{
FINAL RESULTS FROM THE HIGH-CURRENT, HIGH-ACTION CLOSING SWITCH TEST PROGRAM AT SANDIA NATIONAL LABORATORIES
}

\author{
M. E. Savage \\ Sandia National Laboratories ${ }^{\S}$ \\ PO Box 5800 Mail Stop 1194 \\ Albuquerque NM 87185
}

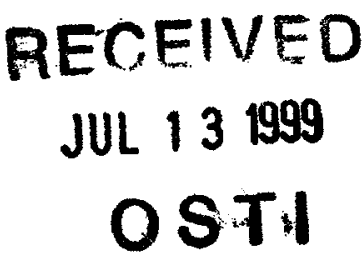

\section{Abstract}

We tested a variety of high-current closing switches for lifetime and reliability on a dedicated $2 \mathrm{MJ}, 500 \mathrm{kA}$ capacitor bank facility at Sandia National Laboratories. Our interest was a switch capable of one shot every few minutes, switching a critically damped, DC-charged 6.2 $\mathrm{mF}$ bank at $24 \mathrm{kV}$, with a peak current of $500 \mathrm{kA}$. The desired lifetime is 24 thousand shots.

Typical of high-energy systems, particularly multimodule systems, the primary parameters of interest related to the switch are: 1) reliability, meaning absence of both pre-fires and no-fires, 2) total switch lifetime or number of shots between maintenance, and 3) cost. Cost was given lower priority at this evaluation stage because there are great uncertainties in estimating higher-quantity prices of these devices, most of which have been supplied before in only small quantities.

The categories of switches tested are vacuum discharge, high-pressure discharge, and solid-state. Each group varies in terms of triggering ease, ease of maintenance, and tolerance to faults such as excess current and current reversal. We tested at least two variations of each technology group. The total number of shots on the switch test facility is about 50 thousand.

We will present the results from the switch testing. The observed lifetime of different switches varied greatly: the shortest life was one shot; one device was still operating after six thousand shots. On several switches we measured the voltage drop during conduction and calculated energy dissipated in the switch; we will show these data also.

\section{INTRODUCTION}

The National Ignition Facility (NIF) would ultimately store 380 megajoules of energy in capacitor banks, and would deliver that energy to flashlamps in a few hundred microseconds. One of several critical elements in that system is the pulsed power closing switch. This switch must withstand $24 \mathrm{kV} \mathrm{DC}$ for tens of seconds, then each switch must conduct $500 \mathrm{kA}$ in a $360 \mu$ s (full-width at half-maximum) pulse. The high peak current and the relatively long pulse together place serious demands on the switch.

Many different closing switches have been developed for pulsed power applications. However, at these operational parameters and desired lifetime, the data are limited. This program was to build a test facility that supplied the voltage and current that the NIF switches would see, in an environment that could readily test and evaluate candidate switches. This test facility closely modeled the NIF circuit, with the exception of resistors instead of flashlamp loads. This full-energy module was dedicated to switch testing and could operate at the rate of one shot per two minutes at $2 \mathrm{MJ}$ stored. This facility has been described more completely in a previous report [1].

There are several commonly used technologies for switching $\mathrm{kA}$ currents and blocking tens of $\mathrm{kV}$. The major groups are vacuum switches, high-pressure switches, and solid-state switches. Each technology has specific strengths. Vacuum switches typically use lowvoltage triggers and have a wide triggering range, but sealed devices are not field-maintainable. High-pressure switches are robust and simple, but have lifetime limitations. Solid-state switches offer the promise of long lifetime, but can be expensive and somewhat delicate. The remainder of this report details the evaluation of different switches for the NIF application.

\footnotetext{
${ }^{\S}$ Work performed at Sandia National Laboratories. Sandia is a multiprogram laboratory operated by Sandia Corporation, a Lockheed Martin Company for the United States Department of Energy under Contract No. DE-AC04-94AL85000.
} 


\section{DISCLAIMER}

This report was prepared as an account of work sponsored by an agency of the United States Government. Neither the United States Government nor any agency thereof, nor any of their employees, make any warranty, express or implied, or assumes any legal liability or responsibility for the accuracy, completeness, or usefulness of any information, apparatus, product, or process disclosed, or represents that its use would not infringe privately owned rights. Reference herein to any specific commercial product, process, or service by trade name, trademark, manufacturer, or otherwise does not necessarily constitute or imply its endorsement, recommendation, or favoring by the United States Government or any agency thereof. The views and

opinions of authors expressed herein do not necessarily state or reflect those of the United States Government or any agency thereof. 


\section{DISCLAIMER}

Portions of this document may be illegible in electronic image products. Images are produced from the best available original document. 
Table 1. Summary of switch test results.

\begin{tabular}{|c|c|c|c|c|c|c|c|c|}
\hline Switch & $\begin{array}{l}\text { Tech- } \\
\text { nology }\end{array}$ & $\begin{array}{l}\text { Shots } \\
\text { tested } \\
\text { (best) }\end{array}$ & $\begin{array}{l}\text { Proj- } \\
\text { ected } \\
\text { life }^{1}\end{array}$ & $\begin{array}{l}\text { Test } \\
\text { current }\end{array}$ & $\begin{array}{l}\text { Test } \\
\text { Voltage }\end{array}$ & $\begin{array}{l}\text { Misfire } \\
\text { rate }\end{array}$ & Issue & $\begin{array}{l}\text { Failure } \\
\text { mode } 2\end{array}$ \\
\hline $\begin{array}{l}\text { NL9000 } \\
\text { (Richardson) }\end{array}$ & ignitron & 500 & 500 & $350 \mathrm{kA}$ & $16 \mathrm{kV}$ & $10 \%$ & Pre-fires, life & mechanical \\
\hline $\begin{array}{l}\text { NL8900 } \\
\text { (Richardson) }\end{array}$ & ignitron & 1300 & 2000 & $250 \mathrm{kA}$ & $12 \mathrm{kV}$ & $5 \%$ & Pre-fires, life & mechanical \\
\hline $\begin{array}{l}\text { ST300 } \\
\text { (MPI) }\end{array}$ & Spark gap & 1500 & 1500 & $525 \mathrm{kA}$ & $24 \mathrm{kV}$ & $.1 \%$ & maintenance & erosion \\
\hline HCS3 (EEV) & $\begin{array}{l}\text { Vacuum } \\
\text { spark gap }\end{array}$ & 650 & 1500 & $525 \mathrm{kA}$ & $24 \mathrm{kV}$ & $.5 \%$ & Life, cost & erosion \\
\hline RPS (Tetra) & $\begin{array}{l}\text { Radial } \\
\text { pseudospark }\end{array}$ & 180 & 180 & $425 \mathrm{kA}$ & $10 \mathrm{kV}$ & $12 \%$ & $\begin{array}{l}\text { Life, prefires, } \\
\text { development }\end{array}$ & erosion \\
\hline $\begin{array}{l}\text { TRA } \\
\text { (Thomson) }\end{array}$ & $\begin{array}{l}\text { Vacuum (rod } \\
\text { array) }\end{array}$ & 90 & 90 & $250 \mathrm{kA}$ & $24 \mathrm{kV}$ & $20 \%$ & life & erosion \\
\hline $\begin{array}{l}\text { RSD } \\
\text { (Arzamas) }\end{array}$ & Solid state & 150 & $\gg 10^{4}$ & $450 \mathrm{kA}$ & $24 \mathrm{kV}$ & 0 & $\begin{array}{l}\text { Development, } \\
\text { cost }\end{array}$ & $\begin{array}{l}\text { thermal } \\
\text { cycling }\end{array}$ \\
\hline $\begin{array}{l}\text { SCR } \\
\text { (SPCO) }\end{array}$ & $\begin{array}{l}\text { Solid state } \\
\text { (125 mm } \\
\text { thyristor) }\end{array}$ & 150 & $\gg 10^{4}$ & $167 \mathrm{kA}$ & $24 \mathrm{kV}$ & 0 & cost & $\begin{array}{l}\text { thermal } \\
\text { cycling }\end{array}$ \\
\hline RAG (MPI) & Spark gap & 6000 & 18000 & $525 \mathrm{kA}$ & $24 \mathrm{kV}$ & 0 & cost & erosion \\
\hline
\end{tabular}

${ }^{1}$ Number of shots before maintenance or replacement (estimate)

${ }^{2}$ Author's opinion

\section{TEST RESULTS}

For all of the testing, the temporal shape of the current pulse was the same. This pulse, shown in Figure 1, varied in amplitude depending on the charge voltage and the number of modules in use. The charge voltage could be varied in less than $100 \mathrm{~V}$ steps; any number of the 25 modules could be used. At a nominal $24 \mathrm{kV}$ charge voltage with the full bank, the peak current is $525 \mathrm{kA}$.

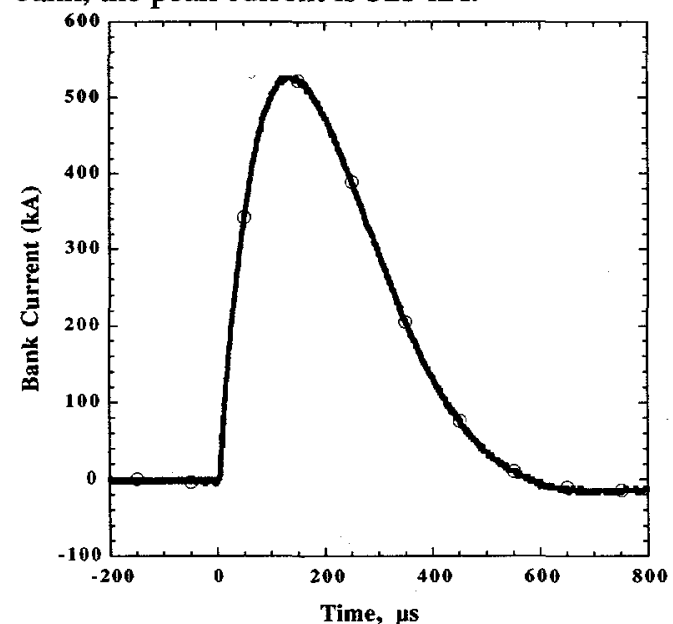

Figure 1. Switch current at $24 \mathrm{kV}$ charge with the full bank.

Table 1 summarizes the results from the switch test program. Some devices were tested in several runs due to scheduling limitations. Note that the spark gaps tested could be re-furbished at the end of life by replacing electrodes. Thus, the total life of a switch could be longer than the electrodelife.

\section{SWITCH TEST COMMENTS}

The results of this testing prompted the decision to use the Maxwell Physics International (MPI) ST-300 [2] spark gap as the baseline switch. This switch has a limited lifetime, but is relatively easy to repair. Repairing the ST300 consists of replacing the graphite electrodes and possibly the fiberglass insulator. Due to the increasing gap as the electrodes wear, the dry air pressure in the switch must be reduced over the lifetime (from approximately 310 $\mathrm{kPa}$ to $35 \mathrm{kPa}$ ).

- Though more expensive, the MPI RAG (rotating arc gap) switch has the advantage of much longer lifetime and few if any pressure changes.

- The solid-state switches are attractive, apart from cost. The relative frailty of solid-state switches means that many pulsed-powerfaults downstream of the switch would destroy the devices, effectively adding to their cost.

- The vacuum switches all had problems due to electrodedamage from arc constriction. Once the magnetic pressure exceeds the plasma pressure and causes a z-pinch-like reduction in the arc diameter, the current density causes electrode 
metal evaporation. In vacuum, the evaporated metal deposits on internal device surfaces, including the insulators.

- The ignitrons and pseudosparks rely on high background pressure to inhibit arc constriction. However, at the parameters tested, the high pressure compromised the voltage hold-off, and even then the arc ultimately constricted (inferred from electrode damage).

Development effort would result in better switches, either similar to ones tested here or new concepts, but clearly it is not trivial to build long-lived switches for this type of service.

\section{ENERGY LOSS MEASUREMENTS}

During testing of the ST300 spark gap, it became obvious that a considerable amount of energy was dissipated in the switch on each operation. The switch was noticeably warm after several shots, and the test rate was limited to one shot per 5 minutes, even with water cooling. There has been work done on switch losses before, but predominately at much shorter time scales [3] or much lower currents $[4,5]$. A set of experiments performed on the switch test facility with several switches addressed the energy loss issue.

The first test was a simple pressure probe installed on the ST300 spark gap. This quartz pressure probe had nanosecond response capability, and the several-hundred millivolt signals were easy to discern. The pressure rise extrapolated to zero time was $2.8 \mathrm{MPa}$ ( $400 \mathrm{psig}$ ). The pressure measurement is shown in Figure 2. This energy, about $20 \mathrm{~kJ}$, was still not enough to explain the heating of the switch.

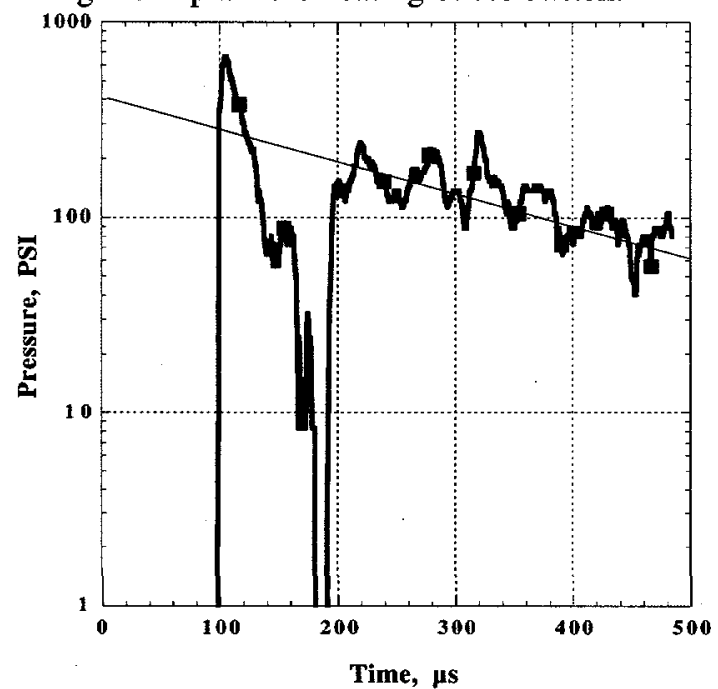

Figure 2. Pressure transducer measurement inside the ST300 gas switch. The sonic transit time to the probe is 100 $\mu \mathrm{s}$.

Making an accurate measurement of the voltage drop during conduction can bedifficult. The measurement system must withstand full switch voltage and then record a small fraction of that voltage while the switch is conducting; the required fraction is about 0.2 percent. This stretches the limits of probe and digitizer settling time. The monitor used here was a commercial unit with a 1000:1 division ratio. The probe was mounted on a ground plane 1.5 meters away from the switch to reduce stray capacity effects. The noise level on the voltage probe was about $30 \mathrm{mV}$, or $30 \mathrm{~V}$ on the scaled signal. The probe operates into $1 \mathrm{M} \Omega$ with a pre-determined length of $50 \Omega$ cable. The probe settling and zero level were checkedwith a 50V, FET switched pulser.

Figure 3 shows the measured current and voltage drop on an ST300 test at full current. The voltage waveform is offscale before the switch is triggered. The shape of the voltage waveform might indicate an incorrect inductance value; however this has no effect at peak current and cancels outof the energy integral.

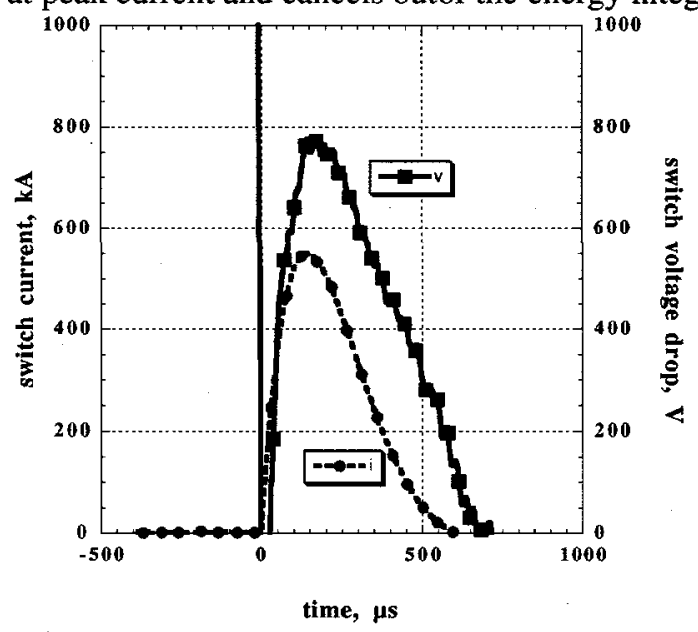

Figure 3. Measured current and voltage drop on a ST300 test at full current.

Figure 4 shows the calculated energy dissipated in the ST300 vs. the peak current.

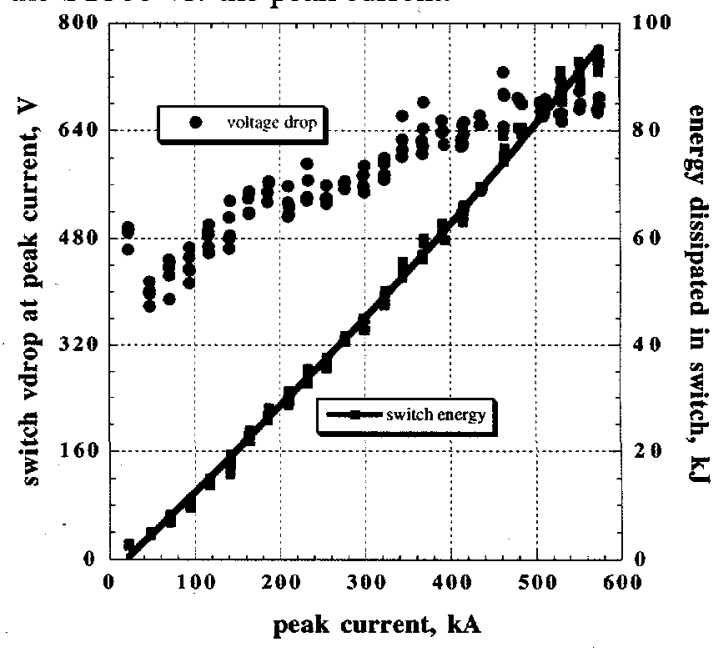

Figure 4. Total energy dissipated in the ST300, and voltage drop at peak current. Five or more shots at each current level are shown. The data shown are at constant $35 \mathrm{kPa}$ pressure.

The voltage drop also shown in the Figure is over $600 \mathrm{~V}$ at $500 \mathrm{kA}$. A similar measurement on the rotating arc gap switch showed similar behavior, but 
losses about 75 percent of ST300 losses at the same pressure. The reason for this difference is not known, but probably is due to the different electrode material (Cu-W vs. graphite in the ST300). Such voltage measurements are difficult, but the calculated energy is close to the approximate energy needed to cause the observed heating of the switch. Figure 5 shows the energy dissipated in the switch over the course of an electrode lifetime. The switch pressure is changed to compensate for the increasing gap. Postulating that the reduced energy losses at large gap are due to the lower pressure (based on testing with constant gap and varied pressure) the resistance was modeled as a constant plus a resistance proportional to absolute pressure to the 0.25 power. This assumes the resistance temporal behavior is unchanging. Due to the long duration of the pulse this is a reasonable approximation. This simple model fits the data within the error bars. This indicates that pressure changes are the dominant cause in energy loss variation; the gap length is a small effect. The actual model used is:

$\mathrm{R}=\mathrm{R}_{\mathbf{0}}+\mathrm{R}_{\mathrm{p}}\left(\frac{\mathrm{p}+\mathrm{p}_{0}}{\mathrm{p}_{0}}\right)^{0.25}$

Here $R$ is the total switch resistance, $R_{0}$ is a constant resistance, $R_{p}$ is the part of the resistance that depends upon pressure, $p$ is the switch fill gas pressure (gauge), and $p_{0}$ is one atmosphere.

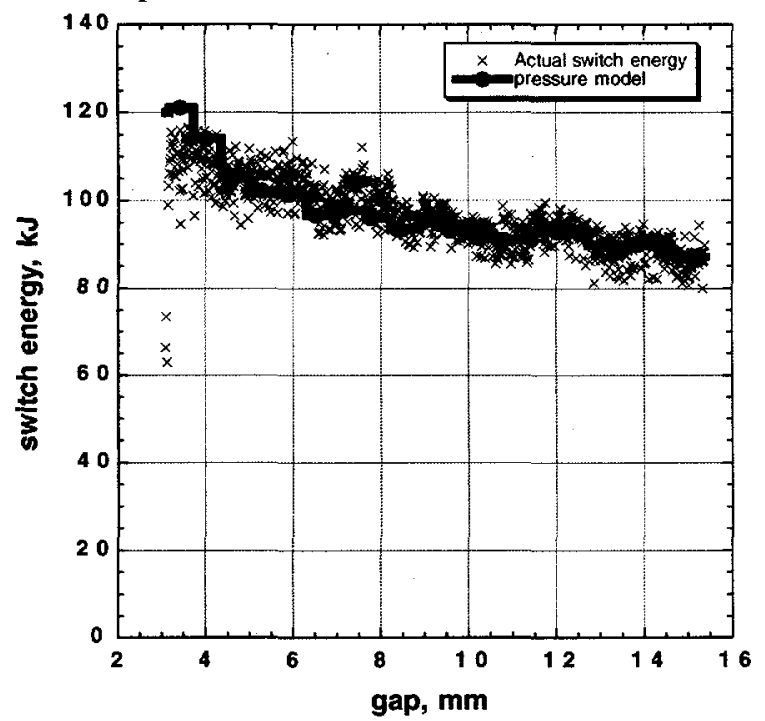

Figure 5. The energy dissipated in the ST300 vs. gap. Both gap and pressure are changing. The pressure model curve includes a resistance term that depends only on pressure.

For the tests with dry air, the values of $R_{0}=.15 \mathrm{~m} \Omega$ and $\mathrm{R}_{\mathrm{p}}=1.2 \mathrm{~m} \Omega$ were obtained. The current pulse action is assumed to be a constant $60 \mathrm{MJ} / \Omega$. This is an empirical fit to these data; a pressure coefficient of 0.33 has been used by others [3].

\section{SUMMARY}

Test results from using a $2 \mathrm{MJ}$ test facility show that switches capable of $500 \mathrm{kA}$ and $360 \mu \mathrm{s}$ pulses do exist.
Lifetime is a serious limitation however. The project requirements, including cost and reliability made spark gap switches the best choice. These switches can be repaired after wear or high-current faults. However, the resistance of the spark gaps is surprisingly high (>1 $\mathrm{m} \Omega$ effective resistance) resulting in $100 \mathrm{~kJ}$ dissipation per shot. Over the limited range tested here, the variation of losses in a given switch depends mostly on pressure and not significantly on gap. A spark gap with coppertungsten electrodes has about 75 percent of the energy losses of a graphite electrode switch. These losses could limit rep-rates of some systems. The solid-state switches have 20 percent of the loss of the discharge switches. Vacuum switches have a common trait of severe erosion with this long pulse, and therefore limited life. Solid-state switches will ultimately replace spark gaps for this type of service, with lower losses and greater reliability. Presently, solid-state devices are considerably more expensive.

\section{ACKNOWLEDGEMENTS}

This effort was a collaborative one. In particular, the author would like to acknowledge the contributions of technicians at Sandia, and D. W. Larson and M. A. Newton at LLNL. The vendors, including Richardson Electronics, Maxwell Physics International, English Electric Valve, Tetra Corp., Thomson Shorts Systems, Arzamas-16, and Silicon Power Corp., have all been exceptionally helpful. The French CEA and English AWE each contributed greatly to construction and operation of the facility.

\section{REFERENCES}

[1] M. E. Savage, W. W. Simpson, R. A. Sharpe, and F. D. Reynolds, "Switch Evaluation Test System for the National Ignition Facility," presented at 11th IEEE International Pulsed Power Conference, Baltimore, Md, 1997.

[2] D. Bhasavanich, S. S. Hitchcock, P. M. Creely, R. S. Shaw, H. G. Hammon, and J. T. Naff, "Development of a compact, high-energy spark gap switch and trigger generator system," presented at 8th IEEE International Pulsed Power Conference, San Diego, Ca, 1991.

[3] T. H. Martin, J. F. Seamen, and D. O. Jobe, "Energy Losses in Switches," presented at 9th IEEE International Pulsed Power Conference, Albuquerque, NM, 1993.

[4] H. Ayrton, The Electric Arc. New York: D. Van Nostrand, 1902.

[5] J. D. Cobine, Gaseous Conductors, Theory and Engineering Applications, 2 ed: McGraw-Hill, 1958. 